\title{
PRELIMINARY OBSERVATIONS \\ ON A TETRADONEMATID NEMATODE \\ OF PHLEBOTOMINE SANDFLIES OF AFGHANISTAN
}

\author{
R. KILLICK-KENDRICK*1, M. KILLICK-KENDRICK ${ }^{1}$,
}

N. A. QALA I NAWI ${ }^{2}$, R. W. ASHFORD ${ }^{3}$, YINSHAN TANG ${ }^{1}$

\section{Observations préliminaires sur un Nématode Tétradonematide, parasite de Phlébo- tomes en Afghanistan.}

SUMMARY. A tetradonematid nematode was found in Kabul, Afghanistan, parasitising Phlebotomus papatasi (Scopoli) and P. sergenti Parrot. The worm was readily established in the laboratory by rearing larvae of $P$. papatasi in pots containing eggs of the nematode. The parasite prolonged or arrested the development of larvae. Infected male flies constantly had unrotated external genitalia and were unable to mate. Infected female flies refused opportunities to engorge. The worm reduced the length of life of adult flies. Further observations are required to assess the potential of the Afghan parasite in the biological control of phlebotomine sandflies.

Key-words: Mermithoidea. Tetradonematidae. Entomophilic nematode. Phlebotomine sandflies Phlebotomus papatasi. Phlebotomus sergenti. Afghanistan.

RÉSUMÉ. A Kaboul, Afghanistan, un Nématode Tétradonematide a été observé chez Phlebotomus papatasi (Scopoli) et Phlebotomus sergenti Parrot. Ce Nématode est actuellement entretenu au laboratoire par l'introduction de ses œufs dans les pots d'élevage de larves de Phlebotomus papatasi. Le parasite semble ralentir ou arrêter le développement des larves. Les genitalia des mâles infestés ne subissent pas la rotation de $180^{\circ}$ habituelle et l'accouplement ne peut avoir lieu. Les femelles infestées refusent de se gorger. La durée de vie des adultes parasités est écourtée. Des observations complémentaires sont nécessaires pour juger d'une utilisation éventuelle de ce parasite afghan dans la lutte biologique contre les phlébotomes.

Mots-clés : Mermithoidea. Tetradonematidae. Nématode entomophile. Phlébotomes. Phlebotomus papatasi. Phlebotomus sergenti. Afghanistan.

\section{Introduction}

In August, 1983, one of us (RWA) found a large, female nematode in the abdominal haemocoele of male and female specimens of Phlebotomus papatasi

* Medical Research Council External Scientific Staff.

1. Department of Pure and Applied Biology, Imperial College at Silwood Park, Ascot, Berks SL5 7PY, England.

2. National Institute for Malaria and Leishmaniasis Control, Kabul, Afghanistan.

3. Department of Parasitology, Liverpool School of Tropical Medicine, Pembroke Place, Liverpool L3 5QA, England.

Accepté le 20 juin 1989. 
(Scopoli) and P. sergenti Parrot collected in Kabul, Afghanistan. The worm was assigned to the family Tetradomatidae Cobb but the internal structures of the worms were too poorly preserved for identification to the genus and they remained undescribed.

Five years later, we found the worm again while collecting $P$. papatasi and $P$. sergenti in Kabul to set up laboratory colonies. One male specimen of $P$. papatasi reared from the eggs of wild-caught sandflies was infected with a single, large female nematode similar to those found in 1983. Larvae of a laboratory colony of $P$. papatasi were infected by rearing them with the eggs of the worm and, in the present paper, an account is given of the collection and maintenance of the nematode and preliminary observations on its effect on the sandfly. In a later publication, the nematode will be described and named.

\section{Materials and methods}

Sandflies were collected either by active searches with aspirators in houses during the day (1983) or with CDC miniature light traps set up overnight inside houses (1988). Sandflies caught in Kabul on the nights of 7 June (at Chehell Saton), 9 June (at Kacha Baghra) and 10 June, 1988 (at Khayr Kana) were taken to Imperial College, Ascot, to establish laboratory colonies. The flies were transferred from the cages of the traps to 5 plastic pots $(8 \mathrm{~cm}$ high, $9 \mathrm{~cm}$ in diameter) with 3 holes $(1.2 \mathrm{~cm})$ cut in the base. The pots were lined with plaster of Paris and kept moist by standing them on damp filter paper. They were closed with fine gauze held in place by the lid. Fresh aqueous sucrose solution (1:1 vol/vol) was given daily on cotton wool put on the gauze. From 12-15 June, the flies were hand-carried in an insulated bag to Ascot. Over half survived the journey. Live females were released into a cage and were offerred a bloodmeal on an anaestheeized hamster. After $24 \mathrm{~h}$, engorged females were tubed individually to obtain eggs for laboratory colonies. Many of the females which had died in transit had laid eggs in the pots. They were left to hatch and the larvae were reared to adults.

$P$. papatasi used for experimental infections were from two colonies. One was set up with the eggs of two females of a batch collected in Cyprus by Dr D. M. Minter in July, 1985. The other originated from sandflies collected in Aurangabad, Maharashtra State, India in 1972 (Tesh \& Modi, 1983). The colonies were reared by the methods described by Killick-Kendrick et al. (1979) except that the larval food was a composted mixture of rabbit faeces and commercially available rabbit food (Young et al., 1981).

To maintain the nematode, mature female worms or a suspension of eggs dissected from a worm in phosphate buffered saline ( $\mathrm{pH} 7.2)$ were put in plastic pots lined with plaster of Paris together with mature eggs or 1st instar larvae of $P$. papatasi. Pots containing infected larvae were kept at $24-25^{\circ} \mathrm{C}$ in a closed plastic box lined with damp filter paper. As adult flies emerged in the pot, they 
were released in a suspended gauze cage. Sucrose solution (1: $1 \mathrm{vol} / \mathrm{vol})$ was given on cotton wool and changed daily. To maintain a high humidity, the cage was enclosed in a plastic bag with a Petri dish of damp cotton wool.

\section{Results}

Observations in the field. In 1983, approximately $1 \%$ of male and female $P$. sergenti and $P$. papatasi collected in Kabul were infected with gravid females of the nematode. Only one female worm measuring 3-4 $\mathrm{mm}$ in length was found in the haemocoele of any sandfly (fig. 1). The worms were almost entirely filled with round, light brown eggs with a strongly sculptured surface and containing

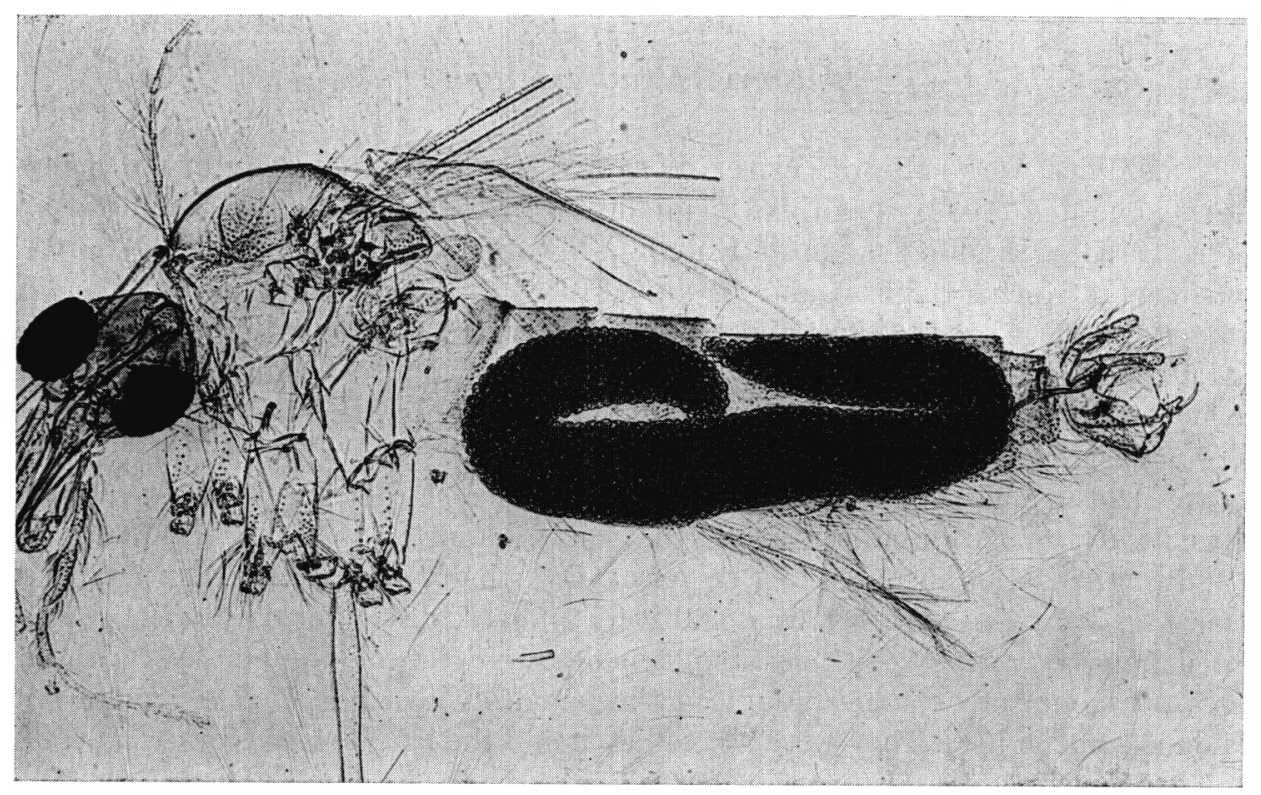

Fig. 1. - Male P. sergenti from Kabul infected with a single female tetradonematid; the external genitalia are unrotated $(\times 40)$.

an undeveloped zygote (fig. 3). Two mounted sandflies burst releasing 4 and 12 minute shrivelled male worms $300-500 \mu \mathrm{m}$ in length and bearing a single comparatively enormous spicule.

The genitalia of infected male flies were always unrotated (fig. 1, 2) which at first wrongly led us to believe that they were all young flies and that the worm killed the fly within $24 \mathrm{~h}$ of emergence.

During dissections in Kabul in 1988, only one female sandfly (unidentified) was found infected, again with a single female worm which unfortunately 


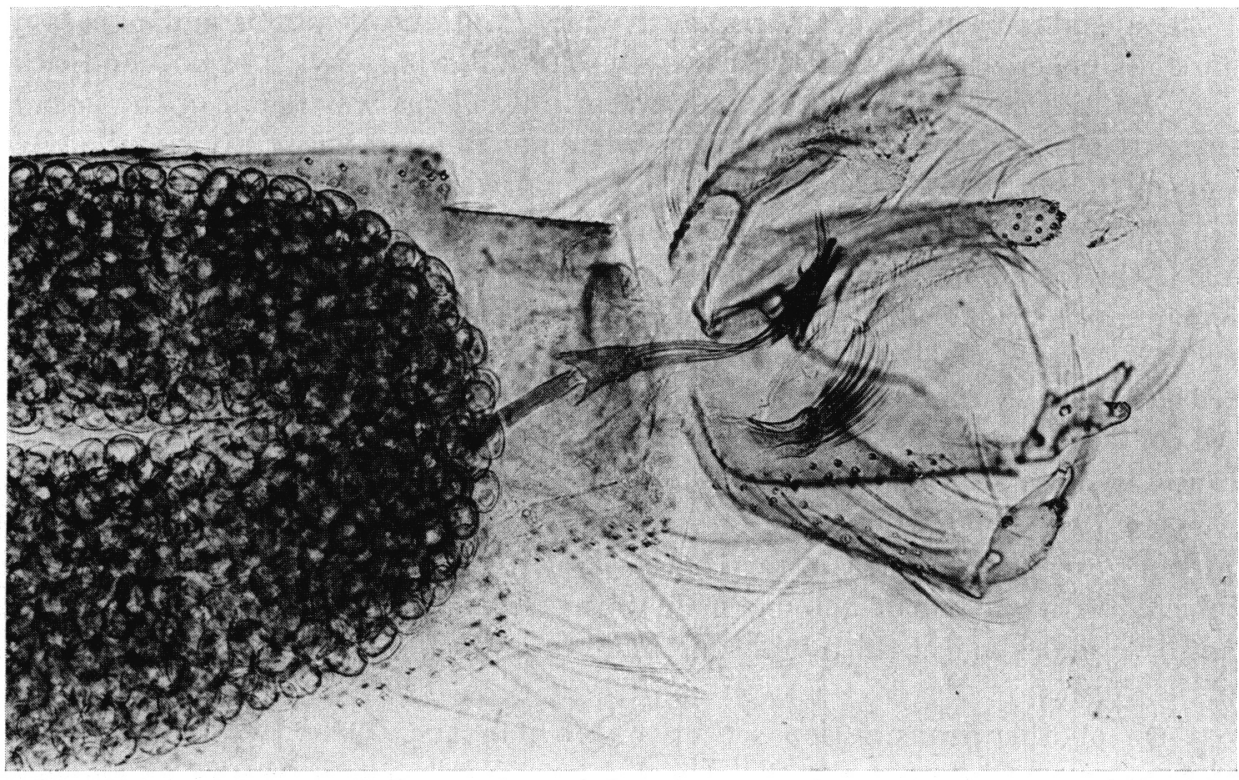

FIG. 2. - Unrotated genitalia of male P. sergenti from Kabul infected with a single female tetradonematid which is full of eggs $(\times 170)$.

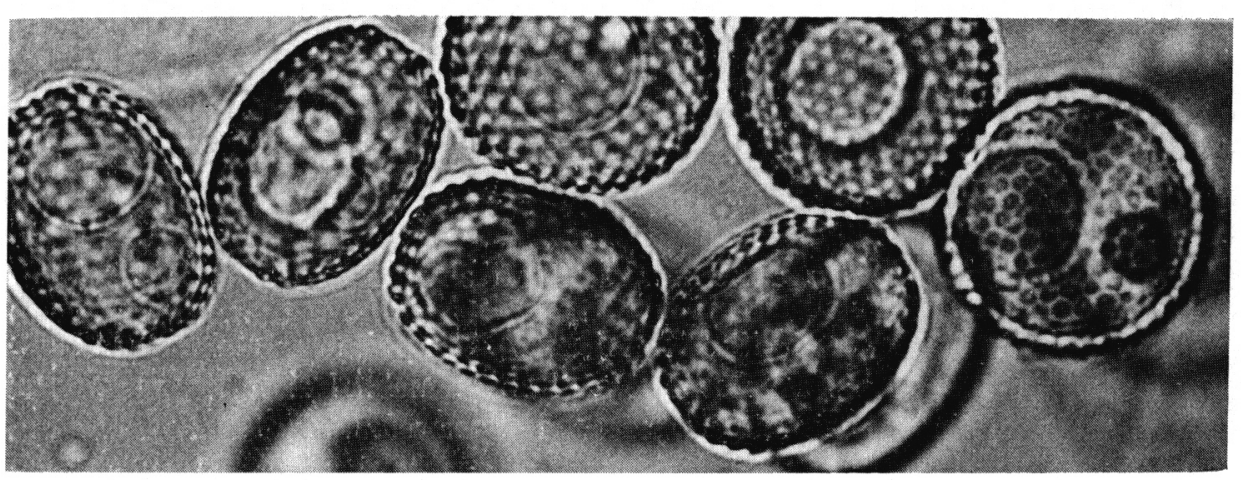

FIG. 3. - Eggs of a tetradonematid of phlebotomine sandflies of Afghanistan $(\times 600)$.

disintegrated during dissection. The infected fly was in a batch caught on Gul ab Chakran on the night of 29 May, 1988.

Observations in the laboratory. The species in the catches taken to Ascot were later found to be $P$. papatasi, $P$. sergenti and P. kabulensis Artemiev. Flies reared from eggs laid in the pots during transit from Kabul to Ascot were pooled in a cage to let them mate and engorge on an anaesthetized hamster. On 11 August, 
1988, a male specimen of $P$. papatasi with unrotated genitalia and a notably dark abdomen was seen in the cage. On the following day, it was found dead and was dissected. One large, female worm full of eggs was found in the haemocoele. It was teased apart and the eggs were put in a pot with fully embryonated eggs of $P$. papatasi. Larvae hatching in the pot were reared to adults.

The first four adults, one female and three males, emerged on 29 September, 1988. On dissection, none was found infected. From 5-27 October, 1988, three females, seven males, three pupae and four 4th instar larvae were dissected and each was found infected with a single female worm. All infected males had unrotated genitalia. A further 3 females and 4 males were mounted in Berlese's fluid. All contained a single female worm. Two male worms of the same size and appearance as those seen in 1983 were found in one of the larvae.

On 19 October, 1988, eggs from a nematode were again put with eggs of $P$. papatasi. Of three 4th instar larvae dissected on 5 December, 1988, one was infected with one female and one male worm, a second with two immature females and two males and a third with one immature female, one male and two larvae of the worm.

On another transmission set up on 16 January, 1989, two female worms were put intact into a pot with 1 st instar larvae and mature eggs of $P$. papatasi. Larvae were seen eating the worms. A total of eight nematodes, three female and five male, were later recovered from one of several 4th instar larvae left in the pot a week after the last emergence of infected adult flies. Heavy infections appeared to prevent pupation.

An experiment was done to find out how much the worm delayed the growth of preimaginal stages and to see if the external genitalia of male flies remained unrotated for life. Two pots of 1 st instar larvae of $P$. papatasi were sown with eggs from nematodes dissected from two experimentally infected sandflies. The larvae were reared to adults and the days of emergence of infected and uninfected flies were compared.

Of 280 emerging sandflies, $62(22 \%)$ were infected with the nematode (Table I). A comparison of the numbers of emerging uninfected (218) and infected (62) flies of both sexes up to Day 29 shows that the nematode infection prolonged

TABLE I. - Numbers of male and female sandflies (P. papatasi) and percentages with or without a nematode infection emerging over a period of 29 days from the first emergence.

\begin{tabular}{lrcr}
\hline & Males & Females & Totals \\
\hline Uninfected & $128(83 \%)$ & $90(71 \%)$ & $218(78 \%)$ \\
Infected & $26(17 \%)$ & $36(29 \%)$ & $62(22 \%)$ \\
\hline Totals & 154 & 126 & 280 \\
\hline
\end{tabular}


the developmental time of the preimaginal stages (fig. 4). The first infected flies emerged 10 days after the first uninfected flies, by which time 193/218 (89\%) of the uninfected flies had already emerged. If the day the first fly emerged is considered as Day 1, the mean days of emergence over a period of 29 days are $6.65 \pm$ SD 4.17 for uninfected flies and $15.87 \pm$ SD 2.86 for infected flies. On average, therefore, the developmental time of infected preimaginal stages was prolonged by nine days. No flies emerged between Days 29 and 49 when there were 9 infected 4 th instar larvae and 33 pupae left in the pots. Two infected males emerged on Day 50 and two males and a female on Day 53; the rest failed to develop further.

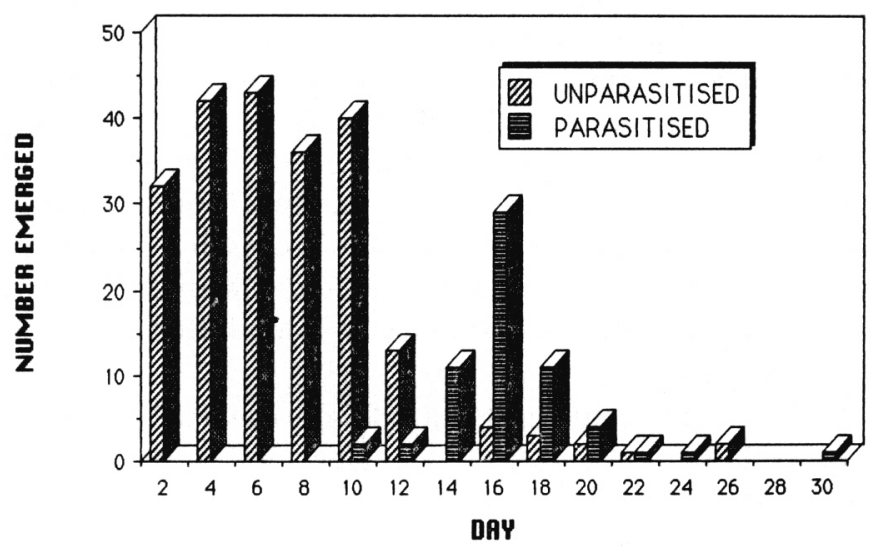

FIG. 4. - Numbers of sandflies (P. papatasi) emerging with or without a nematode infection over a period of 29 days from the first emergence.

As male flies emerged, they were tubed individually and maintained on at $24^{\circ} \mathrm{C}$ on sugar solution. Infections of the nematode were noted and, as the flies died, the state of the external genitalia was recorded. Those of all infected males remained unrotated throughout their lives whereas those of all except one uninfected male rotated to the normal position. It was incidentally noted that the mean lifespan of 116 uninfected males was $21.63 \pm$ SD 8.22 days whereas that of 24 infected males was only $10.75 \pm$ SD 5.64 days.

Infected females caged with uninfected males from the colony constantly refused opportunities to engorge on an anaesthetized hamster.

\section{Discussion}

Large gravid female nematodes similar to the Afghan parasite have previously been recorded in $P$. papatasi, $P$. sergenti and Sergentomyia clydei (Sinton) of Pakistan (Lewis, 1967), P. sergenti, S. clydei and S. christophersi (Sinton) of Saudi Arabia 
(Buttiker \& Lewis, 1983), and S. adleri (Theodor), S. bedfordi (Newstead) and S. schwetzi (Adler, Theodor \& Parrot) of Uganda (Barnley, 1968). None was experimentally transmitted in the laboratory nor were the worms identified. Buttiker and Lewis (1983) suggested that the nematode of the Saudi Arabian sandflies was possibly a tylenchid or a member of a related family. The Afghan worm was identified as a tetradonematid by Dr G. Poinar from photographs of the worms found in 1983 and by Dr W. M. Hominick from an examination of the worms in experimentally infected $P$. papatasi.

Free-living stages of tetradonematids consist of the eggs and the short-lived juveniles. The worms are typically parasites of Diptera and the five generally accepted genera are all monospecific (Poinar, 1975). The nematodes inhabit the abdominal cavity of the host which is usually killed when adult females emerge. The Afghan worm causes delayed or, when heavily infected, arrested development of the sandfly larvae and pupae and shortens the life of infected adults. Male flies are unable to mate because their external genitalia never rotate, and female flies do not engorge and, therefore, cannot produce normal numbers of eggs. However, $P$. papatasi sometimes develops a few eggs by autogeny in the first gonotrophic cycle and one infected female was found with 264 th stage eggs suggesting that the nematode does not completely inhibit the ovarian development of autogenous individuals.

Further studies on the Afghan nematode are needed to assess its potential for biological control. In particular, it would be interesting to see its effect on sandflies unrelated to the known hosts of the worm such as species of Larroussius Nitzulescu which are proven vectors of visceral leishmaniasis in the Mediterranean Basin and elsewhere, and species of Lutzomyia Franca many of which are vectors of the Neotropical leishmaniases. Furthermore, a knowledge of the full life-cycle of the worm may throw light on the natural breeding places of phlebotomine sandflies about which little is known (see Killick-Kendrick, 1987).

Acknowledgments. - The field work was carried out while RWA and RK-K were WHO Short Term Consultants in Afghanistan for WHO, Eastern Mediterranean Regional Office, Alexandria, Egypt. The laboratory work was supported by MRC, London and WHO, Geneva. We are especially grateful to Dr W. M. Hominick and Dr G. Poinar for advice on the identity of the nematode.

\section{REFERENCES}

Adler S., Theodor O. : The distribution of sandflies and leishmaniasis in Palestine, Syria and Mesopotamia. Ann. Trop. Med. Parasitol., 1929, 23, 269-306.

BARnley C. R. : 1968. In: Buttiker \& Lewis (1983).

Buttiker W., Lewis D. J. : Insects of Saudi Arabia. Some ecological aspects of Saudi Arabian phlebotomine sandflies (Diptera: Psychodidae). Fauna Saudi Arabia, 1983, 5, 479-528.

Killick-Kendrick R. : Breeding places of Phlebotomus ariasi in the Cevennes focus of leishmaniasis in the south of France. Parassitologia, 1987, 29, 181-191.

Killick-Kendrick R., Leaney A. J., Ready P. D. : The establishment, maintenance and productivity of a laboratory colony of Lutzomyia longipalpis (Diptera: Psychodidae). J. Med. Entomol., 1977, 13, 429-440. 
LEwis D. J. : The phlebotomine sandflies of West Pakistan (Diptera: Psychodidae). Bull. Br. Museum (Natural History) (Entomol.), 1967, 19, 1-57.

Poinar G. O. : Entomogenous nematodes, Leiden: E. J. Brill, 1975, 317 p.

Tesh R. B., Modi G. B. : Growth and transovarial transmission of Chandipura virus (Rhabdoviridae: Vesiculovirus) in Phlebotomus papatasi. Am. J. Trop. Med. Hyg., 1983, 3z, 621-623.

Young D. G., Perkins P. V., Endris R. G. : A larval diet for rearing phlebotomine sandflies (Diptera: Psychodidae). J. Med. Entomol., 1981, 18, 446.

\section{BULLETIN D'ABONNEMENT}

\section{Annales de Parasitologie}

OUI ! Je m'abonne aux Annales de Parasitologie 1989.

Les abonnements partent du premier numéro de l'année - 6 numéros par an -
1180 FF France
Étudiants $590 \mathrm{FF}$
239 US $\$$ Étranger

Je joins mon règlement à l'ordre de SPPIF (pour les pays étrangers : consulter page 321 pour connaître le nom du distributeur pour chacun de ces pays).

$\square$ chèque bancaire

$\square$ CCP 2 volets

$\square$ prélèvement automatique* : envoyez-moi un formulaire

Nom :

Prénom :

Adresse :

Code postal : Ville :

Pays

Spécialité :

Bulletin d'abonnement à retourner à : S.P.P.I.F., B.P. 22, 41353 Vineuil

* Offre réservée à la France métropolitaine. 